\title{
Estética e cibercultura: arte no contexto da segregação dromocrática avançada
}

EugÊNIO TRIVINHO

Programa de Estudos Pós-Graduados em

Comunicação e Semiótica PUC - SP 


\section{Resumo}

O ensaio contextualiza e problematiza, não sem intenção polêmica, a relação entre estética e suportes virtuais no mencionado recorte socialhistórico - o dos anos 90 em diante -, priorizando os pressupostos, as contradições, os paradoxos e os horizontes tecnológicos e artísticos implicados. A partir da dissecação do modus operandi da cibercultura (articulado por um neodarwinismo dromocrático de proporções mundiais) e da crítica ao ciberufanismo estético internacional (que faz a arte participar, involuntária e indiretamente, da segregação social fundada na informatização e na interatividade), o texto provê, como contribuiçã̃o ao debate, novos indicadores conceituais para apreender a redefinição que o estatuto e o papel cultural da produção artística de ponta sofreu no contexto contemporâneo.

\section{Palavras-chave}

cibercultura, neodarwinismo dromocrático, estética, ciberufanismo, princípio da politização

\section{Abstract}

The essay puts into context and problematizes, not without provocative intention, the relation between aesthetics and virtual supports in the above mentioned socio-historical outline - the one from the nineties on -, prioritising the technological and artistic premises, contradictions, paradoxes and horizons involved. From the dissection of cyberculture's modus operandi (articulated by a worldwide dromocratic neodarwinism) and from the criticism of international aesthetic cybercelebration (which involuntarily and indirectly involves art in the social segregation based on the widespread use of information technology and interactivity), the text provides, as a contribution to the debate, new conceptual indicators for the understanding of the redefinition that the 'statute' and the cultural role of the state-of-theart artistic production has undergone in the contemporary context.

\section{Key words}

cyberculture, dromocratic neodarwinism, aesthetics, cybercelebration, principle of politicisation 
A MARCA DE UMA MORDIDA em lugar algum.

Também a ela tens de combater, a partir daqui. Celan $\left(1999\right.$, p. 123) ${ }^{1}$

A identidade estética deve defender o não-idêntico que a compulsão à identidade oprime na realidade. Adorno (1970, p. 15)

\section{Nota introdutória}

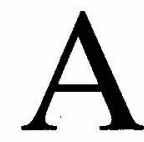
ninguém que tenha se dedicado à história da cultura escapa o fato de que a autonomia da arte sempre foi precária. Refém sistemática do finalismo fetichista na ordem tribal, da racionalidade transcendental da iconografia cristã, da astúcia filantrópica da custódia aristocrática, do maneirismo mercantil da burguesia abastada, do nepotismo mítico da raça ariana e da cooptação ideológica em nome do proletariado, a arte viu-se, a partir de meados do século passado, imersa em seu cativeiro mais sedutor: parceira indispensável do processo de produção e/ou senhora de sua própria trajetória no capitalismo, segue tutelada pelas leis do mercado, articulada, a partir de dentro, pela linguagem dos negócios (Trivinho, 2001b). A insistência tardia dessa circunstância histórica atirou-a, com efeito, num emaranhado não menos comprometedor $e$, ao que tudo indica, de tendência longeva: o mencionado jugo, na fase tecnológica mais avançada da vida humana, se refrata, cumulativamente, na fusão - não raro desacompanhada de tratamento conceitual mis acurado - entre estética e suporte hipermediático,

1. Destaques da edição original. 
assim tornado isento de toda reserva crítica.O fato, que, salvo juízo mais completo, foi até agora pouco notado, tem óbvia inserção na grade de reflexões teóricas sobre a cibercultura, tal como adiante caracterizada. Todavia, os principais núcleos temáticos aí pressupostos não têm sido apropriada ou satisfatoriamente tratados, do ponto de vista da categoria da crítica teórica, na literatura ensaística disponível. Por certo, desde, ao menos, meados dos anos 80, a produção teórica sobre a cibercultura é pródiga. Em torno dela, vê-se, aliás, reacender a fermentação intelectual antes intensamente coagulada no debate internacional sobre a sociedade pós-industrial e, anos mais tarde, cumulativamente, sobre a relação entre a modernidade (e seu projeto) e a cultura pós-moderna. Essa notação, entretanto, segue de par com a evidência de que expressiva parte das intervenções ensaísticas atuais sobre arte e cibercultura ancora-se numa metodologia descritivo-constatatória e/ou terminológico-classificatória, muitas vezes não sendo senão um panegírico (mesmo quando velado), flagrantemente laudatório, em prol das tendências da época, no todo ou em parte -, neste último caso, com o referendo, quase sempre tácito, a algum aspecto prático então tomado como vantajoso. Além disso, não é difícil perceber que os termos do debate estão mal colocados.

Mutatis mutandis, esse arrazoado se projeta, com enfática validade, para as formas cibertecnológicas de presença da produção estética, aí inclusa a sua correspondente representação teórico-epistemológica.

Nas áreas de Ciências Humanas e Sociais, mormente no âmbito da Comunicação - que se tornou locus científico e cultural privilegiadamente estratégico para a compreensão da dinâmica e da estética da civilização contemporânea, suplantando, nesse pormenor, nas últimas três décadas, até mesmo o potencial então granjeado, durante século e meio, pela Sociologia e, há mais de dois milênios, pela Filosofia -, é urgente, pois, a conjugação de esforços teóricos de avaliação de ambos os problemas e, sobretudo, das estratégias epistemológicas e práticas voltadas para a sua, senão superação, ao menos mínima neutralização. $O$ presente ensaio pretende contribuir, no que puder, para suprir essa 
lacuna $^{2}$. Não por outra razão, ele se dedica às estruturas e condições contextuais de base (sociais, culturais e transpolíticas) da relação entre estética e tecnologia comunicacional avançada, no que concerne, especificamente, à situação da produção artística inovadora em sua relação com os materiais e suportes digitais e, por dedução, com a própria natureza e tendências do contexto socialhistórico no qual e a partir do qual se realiza tal produção ${ }^{3}$. Em termos mais precisos, o estudo demanda a caracterização problematizadora dos aspectos de fundo - não raro, objetos de olvido - implicados no recorte assinalado, pressupostos sine qua non que, envolvendo as contradições, os paradoxos e/ou as aporias da dinâmica simbólica do contexto, exercem, em reverso, direta ou indiretamente, pressão sobre o estatuto, o papel $e$ o destino da produção artística na cibercultura. Tais aspectos de fundo estão diretamente relacionados à dimensão mais sutil dos processos simbólicos calcados na lógica invisível da velocidade (cf. Virilio, 1984a, 1984b, 1984c, 1996, 2002).

Não se trata, pois - fique previamente assente -, de reflexão teórica sobre a arte propriamente $\operatorname{dita}^{4}$. Com efeito, a leitura, pelo

2. A perspectiva teórica e epistemológica aqui adotada põe-se na esteira de diversos escritos (do autor) sobre a condição, o estatuto e o destino da crítica teórica na civilização mediática avançada. No que isso diz especificamente respeito à cultura pós-moderna e à cibercultura, alguns desses trabalhos foram reunidos em Trivinho (2001a), outros permanecem esparsos em coletâneas e periódicos científicos brasileiros.

3. A argumentação envolve, em único fôlego - e isto não sem a devida consciência do autor acerca da eventual impropriedade desse procedimento, não obstante ser ele o mais adequado a diminutas condições de espaço -, o arco de ramificações e propostas estéticas abrangidas pelo conceito de arte digital ou ciberarte, que sinonimizam, mutatis mutandis - haja ou não direto vínculo com o cyberspace -, com os conceitos de arte virtual, arte numérica, arte hipermediática, arte hipertextual, arte interativa, arte telemática, Web art, "artemídia" avançada, arte fractal, arte holográfica eletrônica, infografia e demais variantes.

4. O argumento é encaminhado menos por motivos de ordem metodológica do que por dever de ética no âmbito da produção intelectual. Consigne-se que, não sendo o autor propriamente um artista, no rigor histórico e profissional da palavra - muito cedo, após célere passagem pela literatura e outras artes, trarisitou ele desse universo de expressão para o campo igualmente aberto da reflexão teórica -, o lugar da elaboração epistemológica a partir do qual se tece a presente contribuição e se vislumbra saldar a lacuna antes mencionada só poderia ser, no caso, o da perspectiva esboçada, centrada, frise-se, no contexto social-histórico contemporâneo e na condição da arte nele. 
prisma do social-histórico, do que de sociotécnico se projeta na arte digital é, em si mesma, argumentação de contextualização dessa mesma produção; e, sem dúvida, tal leitura constitui, em filigrana, e provê, significativamente, argumentação sobre a arte propriamente dita ou sobre aspectos que lhe são identitários. (Inversamente, uma reflexão teórica centrada nos materiais e suportes da arte virtual é, pelo mesmo prisma, simultânea e necessariamente, reflexão sobre os fatores contextuais aos quais os materiais e suportes estão, umbilical e incondicionalmente, atados.) Evidentemente, a condição epocal da arte não será devidamente apreendida exceto se tomar como objeto de dissecação a especificidade tecnocultural de seu próprio cenário.

\section{Cibercultura: dromocracia ${ }^{5}$}

A fim de cumprir a agenda prevista, tece-se, a seguir, um conjunto de considerações sobre a cibercultura e suas relações com a dromocracia, o terror e as novas formas de segregação social. $\mathrm{Na}$ seqüência, retomar-se-á a questão da arte.

\section{Dromocracia cibercultural}

A noção de cibercultura nomeia a fase contemporânea da civilização tecnológica. Abrange, como bloco social-histórico, o estirão mais avançado da mundialização do capital, fincada nas tecnologias do virtual e em redes interativas. Não marca, portanto, tout court, uma nova era; confunde-se, antes, com ela: é-a. Assim encarada - em sua real amplitude, vale dizer, como universo material, simbólico e imaginário não redutível aos processos exclusivamente constatados na interioridade do

5. Não sendo possivel, no momento, o detalhamento da temática deste tópico - não constitui ela, aliás, o objeto precipuo da reflexão -, vale registrar que uma análise completa a respeito encontra-se em Trivinho (2001a, p. 209-227, 2002, 2003). Cumpre-se, na seqüência, uma sinopse reescalonada do essencial sobre a matéria. 
cyberspace $^{6}$, como sói fazer a literatura ensaística especializada, no Brasil e no exterior -, a cibercultura radica no próprio contexto $a$ priori de relação com os media e redes interativos, com o imaginário socialmente erigido a partir deles, em torno deles e para eles, com os discursos e práticas (inclusive as referentes aos usos sociais) que os promovem e com as linguagens específicas que representam e que doravante precisam ser dominadas.

A cibercultura é talhada, de ponta a ponta, pela dromocracia. O conceito de dromocracia, cunhado por Virilio, em 1977, num contexto de discussão sobre as relações entre campo político e campo bélico no âmbito da história ocidental ${ }^{7}$, refere-se a uma dinâmica societária subordinada ao imperativo da velocidade. Como tal dromos, prefixo grego, significa rapidez, agilidade -, o conceito abrange as profundas mudanças por que a vida humana tem passado nas últimas décadas, em função da aceleração tecnológica levada a cabo em todos os setores (esfera da produtividade, mercado de trabalho e de consumo, comunicação, urbanização, modelos e modismos, relacionamentos e assim por diante). Sob a tutela dromocrática, o mundo e seus pertences, na cibercultura, liquefazemse em lapso de tempo historicamente ultracurto, a efemeridade não se alçando senão, como valor, à condição de "útero" de todas as coisas e, simultaneamente, também de seu epitáfio ${ }^{8}$.

A matéria merece sucinta inflexão no âmbito diacrônico. Se a lógica da velocidade sempre pautou a existência humana, nem sempre, porém, constituiu-se como regime específico, vale dizer, como

6. O termo segue no original inglês por razões de política da teoria (id., 1999, Introdução, tópico III). Ao que provém do campo bélico e em torno de cuja origem se insiste em produzir, mormente na área de Comunicação, um estranho olvido não cabe tratamento epistemológico condescendente, sob pena de inocência política.

7. Espectro temático fundamental de Velocidade e política, conforme dados bibliográficos mais adiante.

8. No fundo, é o vetor dromológico, tal como vislumbrado por Virilio, que contextualiza, com originalidade epistemológica, a célebre passagem de $O$ manifesto comunista, de Marx (como, de resto, o pensamento deste sobre a função socialhistórica da "classe social detentora dos meios de produção"), segundo a qual, no reino do capital, "tudo o que é sólido desmancha no ar", mote mais tarde retomado por Berman (1987), como metáfora da modernidade industrial. 
eixo estrutural de reconfiguração e reescalonamento de sentidos existenciais e valores sociais, hábitos e práticas, relações e processos. Nos marcos do presente estudo, a dromocracia é, no rigor da palavra, fenômeno antropológico e sociotranspolítico que aflora apenas em condições históricas especiais, infotecnologicamente saturadas. A mutação observada no estatuto sociocultural e político-econômico da velocidade no transcurso dos últimos séculos, sobretudo a partir do advento da fase industrial da formação capitalista e, mais tarde, (do advento) da configuração mediática da vida social - uma enorme mudança: grosso modo, de princípio de modulação de práticas a vetor prioritário de projeção e modulação de toda uma dinâmica sociotecnológica -, demarca pari passu o talhe social-histórico da dromocracia como estrutura dinâmica que refunda a questão da hierarquia em escala planetária ${ }^{9}$. Vice-versa, 'a emergência da dromocracia, tal como aqui caracterizada, assinala, ao mesmo tempo, o reescalonamento formal, embora sutilizado, e a nebulosa banalização, em vias de saturação terminal, do vetor da velocidade ao nível intersticial da vida cotidiana, desde a esfera do trabalho à do tempo livre. Nessa esteira, ao longo das últimas três décadas, a dromocracia entrou em sua fase cibercultural ${ }^{10}$. É, com efeito, equivocada a impressão de que a linha de desenvolvimento de um fenômeno cruzou o percurso histórico do outro. $\mathrm{Na}$ verdade, a cibercultura internacional provém justamente do longevo estirão econômico-dromocrático de industrialização e pós-industrialização ocidental. A cibercultura, como arranjamento societário mais avançado da civilização mediática, tendo otimizado, às últimas consequiências, o vetor da velocidade, com a instituição cotidiana do tempo real interativo, cooptou e fagocitou, em si e para si, em caráter definitivo,

9. Ela reinventa, dentro e fora das nacionalidades, não somente um novo critério de estratificação social, como também a realiza. Veja-se, a respeito, Trivinho (1999, Parte I, Cap. V, 2001a, p. 224-225, 2002, p. 270-271, 2003).

10. A inovação teórica trazida para esse âmbito temático radica justamente no estabelecimento conceitual mais rigoroso dessa relação, traduzida, precisamente, na inserção estratégica do referido conceito no contexto da cibercultura, a fim de melhor apreendê-la e explicá-la. Em outra oportunidade (Trivinho, 2001a, p. 220), registrou-se que "a dromocracia se tornou, mais que tudo, a lógica do regime próprio da cibercultura". 
o modelo dromocrático de funcionamento, dissipando-se, por conseguinte, qualquer distinção ou divisa entre os dois âmbitos considerados. Assim como os media incrustaram-se, para o bem e para o mal, no coração da cultura e de sua produção hodierna - de maneira tal que todo e qualquer estudo sobre estas tenha, doravante, que contemplar, em algum grau de intensidade, mas sempre privilegiadamente, o imperativo comunicacional, sob pena seja de extemporaneidade, seja de anacronismo ou defasamento (cf. Trivinho, 2001a, p. 86) -, a dromocracia vige, com sinete de ferro e fogo, no epicentro da dinâmica descentrada da cibercultura, de modo que qualquer consideração sobre a primeira acaba por ser, via de regra, elocução sobre a segunda, e vice-versa. A dromocracia é o motor invisível da cibercultura. A imperícia metodológica quanto ao valor social dessa relação torna lacunar a reflexão teórica sobre um e outro tema e, bem assim, compromete os resultados atingidos. Sob tais injunções, se, por um lado, a cibercultura já nasceu dromocrática, há razões, entretanto, para, por outro lado, falar-se, com pleonasmo zero, em dromocracia cibercultural (id., 2001a, p. 219-227, 2002, p. 264-271, 2003) ${ }^{11}$. É essa formação sociotecnológica que, mais precisamente - para reciclar um dado lançado acima -, designa, pois, a fase contemporânea do desenvolvimento histórico do capital. Com um detalhe de monta, em geral parcamente notado (e que aqui não pode ser senão destacado en passant): a dromocracia cibercultural é da ordem da transpolítica (id., 2006). A maioria dos processos e fenômenos que nela nascem, se desenvolvem e desaparecem não perpassam mais o território das instituições convencionais da política herdada, tampouco são por elas administráveis ou controláveis. Sob a chancela das formações voláteis, flutuantes, sempre precocemente agônicas, de significação sobremaneira obtusa em sua máxima transparência, a lógica da transpolítica, capilarizada no imperativo informático, enquadra-se na espiral irrefreável, infinita, de ocorrências auto-referentes, anômalas, hipertélicas e nãotranscendentes. ${ }^{12}$.

11. A rigor, pleonasmo haveria se a explicitação do fenômeno se fizesse sob a expressão "cibercultura dromocrática".

12. A temática é retomada mais adiante no contexto da estética. 


\section{Neodarwinismo sociodromocrático cibercultural}

Esse mosaico de fatores começa, com efeito, a revelar a sua real complexidade quando se nota que; ao longo da segunda metade do século XX - sobretudo depois do surgimento da Internet, no final dos anos 60, e do da Web, no início dos 90 -, a dromocracia passou a articular-se, mais definidamente, como terror ${ }^{13}$. Um terror, porém, de feições especiais: à violência dissuasiva própria da política institucionalizada, capitaneada por Estados nacionais, com apoio ou não em organizações multilaterais ${ }^{14}$, e por grupos guerrilheiros, político-religiosos e/ou étnicos a lógica da cibercultura acumula - e mesmo sobrepõe - a ameaça vinculada à sua própria exigência: o imperativo do ser veloz. Impessoal, desprovido de núcleo de gestação e comando, o terror dromocrático-cibercultural traduz-se como coação tecnológica processada nas e pelas injunções das pressões sociais pantópicas, já intensamente introjetadas no e pelo imaginário do capital (esfera da produção e mercado), das instituições e do tempo livre. Ele se recria e pulsa a partir do modo como se configura o social contemporâneo, sobretudo nas metrópoles e cidades de médio porte. Trata-se, por isso, de uma sorte de terror inclinado ao interstício. No que tange às individualidades, ele não provém de fora; gesta-se, antes, de dentro, fustigando, em especial, o que é íntimo: a mentalidade cotidiana, no que nela há de vínculo particularmente com o inconsciente.

O conceito fundamental dessa problemática necessita, cada vez mais, de grifo: dromoaptidão. Conforme especificado em outra oportunidade (id., 2001a, p. 209-227, 2002, 2003), a dromoaptidãode clara ịspiraçã̃o na noção de dromocracia, de Virilio - concerne às condições materiais e propensões subjetivas que, de acordo com o discurso tecnológico da época, precisam ser doravante totalizadas para se consubstanciar o pleno domínio (a partir do domo, no caso

13. Toda a energia dromológica do social gira, doravante - mais além dos próprios media interativos -, em torno da rede imaterial internacional em que se converteu o planeta.

14. Conforme disso nos dão bem notícia Negri e Hardt (2001). 
das individualidades) do objeto infotecnológico (completo e atualizado, incluindo o conjunto de softwares requeridos), da rede interativa (língua inglesa e acesso wireless, via cabo ou mesmo por linha telefônica pressupostos), do estatuto social de ente teleinteragente, do capital cognitivo correspondente e da capacidade de acompanhamento das reciclagens estruturais tanto do objeto infotecnológico, quanto do capital cognitivo ${ }^{15}$. Tais elementos, abrangidos pelo conceito de sociossemiose plena da interatividade (cf. Trivinho, 2003), funcionam, de maneira cada vez mais cerrada, como linguagem tecnológica de acesso (senhas infotécnicas) ao modelo predominante de existência, seja presencial (em geral, na esfera do trabalho e do tempo livre e de lazer), seja virtual [no cyberspace, o mais recente universo tecnossimbólico/imaginário do multicapitalismo tardio, espaço renovado de atuação humana e, portanto, um direito (ainda não devidamente transformado em objeto de Estado e de políticas públicas)].

A voz múltipla e altissonante da época, subordinada a agressivo fluxo publicitário fragmentariamente estandardizado, assim proclama, com inflexão pantópica: se dromoaptidão é ethos interativo, não há, em caso diverso, que se falar em ser. No rigor do conceito, dromoaptidão cibercultural é, portanto, capital social sine qua non, em sua reconfiguração mais recente como capital propriamente simbólico (cf. Bourdieu, 1982, 1983, 2002) exigido para se ser-e, por aí, alcançar-se cidadania (teleinteragente) no mundo. Trata-se de regra sumária, inescapável quanto irrecorrível, que cartografa desde subjetividades individuais a países inteiros, enquadrando, por pressuposto, grupos, instituições e corporações.

Define-se, tout court, nos bastidores desse caleidoscópio de fatores, a contemporaneidade ou a extemporaneidade da relação para com a época e para com a forma da vida nela e por ela

15. Se dromoaptidão é, fundamentalmente, dinamismo eficaz, passivel de comprovaçāo a qualquer momento, doravante tal premissa recai sobre todas as demandas da cibercultura: dos conhecimentos teórico-técnicos às habilidades pragmáticas e capacidades adaptativas, das chances de aquisição e renovação de objetos e produtos ciberculturais às possibilidades de fruição respectiva, e assim por diante. 
incentivada ${ }^{16}$. É a dromoaptidão que; em sua unidade processual, contém, consubstancia e fomenta, a um só tempo e integralmente, a dromocracia cibercultural como fase hodierna da civilização mediática.

A dedução do exposto resulta, de certa maneira, óbvia. A quem ou à instância social que não é concedido o domínio pleno (tanto mais privado quanto possível) das senhas infotécnicas a dromocracia cibercultural cifra a acentuada ameaça de amputação simbólica do devir. Essa condição - a da inexistência do domínio indicado - caracteriza inapelavelmente a dromoinaptidão. É pela recolocação da divisão esquemática entre aptos e inaptos, alicerçada na distribuição social aleatoriamente desigual dos acessos como capital simbólico, que o modus operandi da cibercultura realiza a forma de segregação técnica doravante mais avançada, incomparavelmente mais eficaz, porque impassível de fácil identificável em meio ao emaranhado de sulcos e desvios da pródiga fenomenologia dos processos cotidianos. Sobre o dorso de um indivíduo ou grupo, sobre o conjunto das vigas de uma instituição ou corporação, sobre um país inteiro [assim socialmente considerado(a)] dromoinapto o neodarwinismo cibercultural flexiona o peso de sua violência simbólica: desterro de todos os elementos e setores nos quais e/ou a partir dos quais se forjam os rumos mundiais da existência contemporânea.

Esses apontamentos - para retomar a temática do terror -, embora demarquem o aspecto essencial do problema, não o esgotam. Algo mais relevante precisa ser ainda computado. Se o modus operandi da dromocracia sempre foi da ordem da violência (Virilio, 1996; Trivinho, 2001a, 2002, 2003) e se as tintas desse pertencimento, agora fincado nos vetores da cibercultura, constam acentuadas, a própria dromoaptidão - e não já a dromoinaptidão socialmente produzida - encerra, por conseguinte, a violência em bloco desse mundo, legitimada e irradiada especialmente pelos ventos normativos

16. As senhas infotécnicas de acesso à cibercultura constituem os pilares de um tipo de religare inédito, totalitário, porque indexador e onipresente, fundamento tecnológico de uma nova religião, laica, mercantil e obliterada, que não se dá nem se nomeia como tal. 
da esfera da produção. Um ser veloz, em cujo corpo a dromoaptidão se incrustou como habitus ${ }^{17}$, representa, em estado avançado, como figura psíquica típica da época, a introjeção dessa nova modalidade de violência.

Note-se o que, na ausência de maior aproximação com o processo, tende-se a tomar como contradição: ao mesmo tempo que a época assimila o ser dromoapto à modalidade prioritária de ser, ela dispõe a dromoaptidão como agressão sofisticada. Em outros termos, a cibercultura nos põe de frente com a barbárie e, simultaneamente, nos convida, mediantes ameaças doces, sempre não notadas, a ingurgitá-la. O capital cognitivo necessário à inserção na cibercultura, promovido diuturnamente como solução, não constitui senão, no fundo, problema. Não se trata, absolutamente, de contradição ou paradoxo de época, mas da própria coerência interna desta: violência sofisticada do imaginário tecnológico instituído.

A tutela avançada da aceleração tecnológica em todos os setores sociais acabou, de uma forma ou outra, se convertendo em drama humano requintado, tão invisível quanto difuso, como a maioria dos fatores do contexto do qual ele se nutre.

É nesse quadro que se apresenta, de maneira renovada, a questão da morte simbólica. Pressupondo, no caso, em sua base constitutiva, o terror dromocrático-cibercultural, ela soa, logicamente, como a reverberação social colateral, até agora incontrolada, de boa parte da empiria implicada na explanação anterior.

A forma da morte própria da cibercultura corresponde a óbito desacompanhado da destruição física de corporeidades. Trata-se de falecimento efetivo (de indivíduos, empresas, governos etc.) enquanto em vida - bomba de nêutrons: produção de carcaças no quadro geral da deterioração flexível de tudo o que é espiritual (simbólico). Em termos mais específicos - para uma simples referência àquilo de que se trata -, a ausência da posse plena do acesso ao capital de acesso (ao objeto infotecnológico, à rede e ao capital cognitivo conforme) equivale, no todo ou em parte, à angariação, dia menos

17. Aloca-se, para esse trecho, a significação que ao termo empresta Bourdieu (1982, 1983, 2002). 
dia, de uma pena capital, decreto de desterro no local: morte abstrata, mas efetiva, por denegação pantópica por parte do contexto ${ }^{18}$, por fabricação social de impotência para os acessos requeridos; morte por dromoinaptidão socialmente induzida eliminação simbólica sumária por miséria propriamente informática. Nisso reside, grosso modo, o neodarwinismo sociodromocrático da cibercultura.

\section{Arte: condição social-histórica e função estética}

Tais condições sociotecnológicas, tanto mais por sua gravidade, não somente redefinem, no âmbito político da estética, o estatuto da arte, senão ainda sugerem o reescalonamento de seu papel social e cultural.

Posto que os novos materiais e suportes com os quais e a partir dos quais a arte tem construído a sua imagem mais recente constam aí implicados e, ainda, em virtude de motivos justificados na è pela própria epistème engajada no mapeamento feito, a produção tecnoartística avançada não pode(ria) deixar de levar em consideração as injunções desse cenário, nem de dar respostas esteticamente consistentes a ele. Não podendo (ou não devendo), por constituição originária e/ou por princípio identitário, desvincularse da lógica do entorno - melhor, do estado da arte dele -, não pode (ou não poderia), por conseguinte, esquecer-se dos processos simbólicos invisivelmente predominantes (em especial, o terror dromocrático e a eliminação simbólica em série), sob pena já não tanto de anacronismo, mas, a partir dessa "disritimia" temporal, de ingenuidade política.

18. Sabe-se que corpos e mentes tornados dromoinaptos encontram-se aleatoriamente distribuidos em toda parte. Mesmo que hoje tal condição (de não-acesso, excetuados os casos de auto-exclusão voluntária) represente mercado - haja vista que o caixa de órgãos, empresas e entidades civis responsáveis pela ciberalfabetização social gravita em torno disso - o dromoinapto não é senāo, em geral, objeto de ínfima atenção pública, não raro entrecortada por menoscabo. Contra ele a época faz recair um novo tipo de preconceito, ancorado na absolutização da velocidade como valor social (Trivinho, 2002, p. 269). 
Ciberufanismo estético

A recente trajetória dos fatos torna tal preocupação legítima. Assim como, segundo o célebre axioma estético-estratégico de Benjamin (1978, p. 240), o fascismo da primeira metade do século passado, havia espetacularizado a política - e, nesse caso, a resposta a tal barbárie deveria ser a politização da arte -, as tendências majoritárias da cibercultura acabaram, de certa forma, por cooptar a produção artística em prol de sua própria perpetuação (da cibercultura) e por fazer da arte, em todos os domínios digitais, instrumento da construção da imagem do prọprio futuro (daquela, cibercultura) e de suas possibilidades supostamente legítimas. De maneira tạl que, na atualidade, é impossível não reconhecer que a arte digital acabou por vigorar, involuntariamente, como emblema exponencial das tendências (cada vez mais acentuadas e que, aliás, viraram mote acadêmico) de fusionismo dessimbólico entre ente humano e aparato informático e de, por assim dizer, "promiscuidade" apolítica tácita entre corpo, subjetividade e cyberspace $^{19}$. $\mathrm{O}$ argumento em prol do contrário parecer, há muito, ter perdido o seu momento de validação histórica. Dificilmente contornáveis a médio ou a longo prazo, trata-se de tendências que, salvo melhor juízo, vigoram amputadas da autoconsciência necessária acerca de suas próprias consequiências.

A resultante desse processo de tensão (quase) zero entre sujeito e objeto não se apresenta senão - à falta de melhor expressão - como ciberufanismo estético, procedimento de celebração (direta ou indireta) da dromocracia cibercultural que, traduzido, em essência, no seguir (e na colaboração para) o curso preponderante da época (sob o pressuposto vitalista de que somente a isso se pode chamar

19. A omissão quanto ao fato de que, muitas vezes, é a própria arte que adere, voluntária e desavisadamente, aos declives do contexto, subtrairia, com efeito, boa soma de verdade a qualquer explanação a respeito. A rigor, a arte não tem deixado de contribuir para a (afirmação da) tendência de aceitação social ampliada do suporte (com as implicações antes demonstradas) no qual hoje ela se vê amplamente embrenhada (não raro, sem prontidão reflexiva mais criteriosa) quando, antes, deveria pó-lo sob reserva e suspeita. 
$v i d a$ ), pretende representar o envelhecimento do ideal de politização da arte (agora nos termos assentados adiante).

O fato merece flexão especial, em palavras mais objetivas. A desautorização programada ou a desabilitação aleatória da tensão para com o que, no perímetro da preocupação estética, é próximo el ou íntimo - os materiais e suportes, o projeto e o processo criador, a forma imediata e mediata do existente -, vale dizer, a demissão do que aqui se compreende como o fundamento estratégico da crítica, equivale, no contexto social-histórico da cibercultura, ao crash do princípio estético da arte, isto é, ao desmerecimento desta como vetor antropológico prioritário de explicitação das contradições do existente e de contraponto a ele, e como fonte de (re)criação e proposição de uma autonomia subjetiva mínima, satisfatória, incondicional e, por isso - se se quiser -, autêntica do ser no e perante o mundo. Tudo adquire ar mais sério e inquietante ao se considerar que, em particular, o entrançamento dessimbólico (voluntário ou involuntário) da arte com o cyberspace não deixa de significar, em certa medida, peremptoriamente, "promiscuidade" com o principal eixo de sustentação e reprodução do multicapitalismo cibernético globalizado, pressuposto no mapeamento anteriormente feito. Essa especial injunção lança, em reverso, luz sobre o todo: a significação essencial de uma aderência a materiais e suportes digitais desacompanhada da preocupação sistemática em relação ao âmbito social-histórico não encerra senão reacionarismo ao nível da dimensão política da estética - neo-regressão política por abraço ao futurismo tecnológico, como, de resto, à sua representação publicitária corrente ${ }^{20}$; no sentido diametralmente oposto - aproveitese o ensejo para dizê-lo -, agir segundo o critério da autonomia, da

20. Depois das erosões no tecido da metafísica ocidental pela discussão intemacional sobre o pós-moderno, inaugurada na década de 80 do século passado, tudo o que, em estética e em política, se liga à categoria do futuro prende-se, direta ou indiretamente, à imagem desse neo-reacionarismo típico. Tal premissa, aliás, não deixa de demonstrar o quanto, em regra geral, futurismo em estética representa posição e visão de mundo politicamente reacionárias. Para uma contextualização desse argumento, fincada na relação entre modernidade e pós-modernidade, veja-se Trivinho (2001a, p. 39-78). 
tensão produtiva e, quando o caso, da resistência, tal é a imagem do que, nesse mesmo âmbito, representa (e preserva) avanços em matéria teórica, em prol da autenticidade e da dignidade do trabalho do conceito $^{21}$.

Princípio da politização multilateral - transpolitização do real pela arte

À produção tecnoartística atenta às ciladas e dissuasões desse contexto o horizonte acena com uma mínima mas indispensável possibilidade: a politização da cibercultura, de seus vetores de sustentação (em especial, o cyberspace), de sua lógica dromocrática e de seus prováveis horizontes. Tal politização se cumpre, formalmente, com a ativação permanente de uma categoria incondicional de crítica durante a práxis reflexiva (seja em arte, seja fora dela). Crítica é, a um só tempo, epicentro de mediação imanente do trabalho intelectual; desempenho diuturno de alerta às cooptações do existente e às ilusões em relação ao devir e, sobretudo, procedimento estratégico de tensionamento simbólico. Politização é método teórico-prático específico de relação com o mundo (em sua imediatidade e integralidade), bem como com os seus elementos constitutivos. A crítica compreende, em essência, a politização. A politização, por seu turno, é a dinâmica da crítica, a sua representação cinética, por assim dizer. É a politização que, no fundo, tensiona. Nesse aclive estratégico, a crítica não deixa de ser - à falta de melhor termo - método.

Em palavras contextualizadas, politizar significa, nessa perspectiva, transformar em fonte de questionamento público o que insiste em subtrair-se ao campo da visibilidade, menos por carência de explicitação (fato normalmente assimilado à clássica ocultação) do que por excesso de transparência (o que envolve a produção

21. Trata-se, de toda forma, de questão banalizada. Tal inversão de valores se consumou há bom par de anos, desde que os códigos da informatização, da virtualização e da cibericonização hipertextual se tornaram o paradigma publicitário padrão da cibercultura, e a interatividade, a sua práxis publicitária matricial. 
cultural da obviedade como valor, sempre dissuasiva em função da letargia que instila no conjunto dos sentidos percepcionais) ${ }^{22}$; e, de maneira conjugada, (politizar significa) focar (isto é, estabelecer como destino reflexivo) as tensões inexoravelmente existentes na relação com o objeto em contexto e, ao mesmo tempo, elaborá-las no plano do conceito.

Se, em matéria teórica, somente a categoria da crítica politiza, além da relação com o objeto, o processo de pensamento e a sua fundamentação, a tessitura discursiva, a proposta epistemológica e a relação com os principais interlocutores envolvidos e com as tendências teóricas e práticas do mundo (cf. Trivinho, 2001a, p. 161174), essa politização multilateral tem, em matéria estética, com efeito, expressão obviamente peculiar, a começar pelos precedentes históricos próprios a esse campo. Arte é [ou deve(ria) ser], mais que outra expressão humana, heterodoxia, desconstrução elou ruptura. Do contrário, oblitera-se o que lhe é mais caro: a identidade a si própria, sustentada no pressuposto originário de mutação contínua, seja em seu próprio âmbito, seja no do social-histórico. Nessa perspectiva, tensionamento estético e da estética e, por esta, do real implica em (re)politização multidimensional da arte (tanto em seu momento de concepção, quanto em sua práxis), não, todavia, no sentido de Benjamin (1978), stricto sensu falando - posto que não se trata de política em prol de uma visão teleológica de mundo, como o marxismo, ou programática, como a do partido ou da vanguarda (cuja potência desmoronou nas últimas três décadas, juntamente com o edifício da modernidade) -, e sim, no mínimo, na perspectiva do que está bem além da política de ofício (de direita ou de esquerda), espetacularizada e engessada, forjada no terreno do Estado e de suas instituições, dos media e do mercado. Nisso se encerra expressiva soma do que se pode designar como politização transpolítica. Eis que, quando aqui se evoca a politização estética e da estética, faz-se, a rigor, remissão à transpolitização da arte.

22. O excesso de transparência do mundo - a exuberância (sempre crescente) da explicitação dos signos - logra acerca do fundamental a ser notado; gesta, paradoxalmente, a taxa (quase) nula da percepção relevante. 
Essa associação expressiva, longe de constituir trocadilho, merece comentário extra e especial, conforme segue.

Os conceitos de politização e de transpolítica têm, cada qual, sentido polissêmico no presente ensaio. Com efeito, ambos confluem, de maneira definida, embora, a rigor, vigorem em dimensões diferentes de significação. Há um sentido de transpolítica (cf. Trivinho, 2006) que não pode ser perdido de vista e que, não se reduzindo à mencionada empiria processual, coincide inteiramente com o princípio da politização, sem perda de nexos imanentes de coerência. Se politizar - vale, aqui, a ênfase - significa tensionar a forma de organização sociotecnológica do real por meio da crítica teórica orientada, para além de qualquer vínculo com a política stricto sensu e com o imaginário político instituído - fato que envolve a característica primeira da transpolítica, aquém mesmo de seu traço de escape de todas as formas de administração, gerenciamento e controle por parte das instituições políticas modernas, herdadas do iluminismo francês e do liberalismo inglês do final do século XVIII -, transpolítica, por seu turno, além de equivaler à fenomenologia aleatória do mundo tecnológico, inclui, em seu conteúdo, como procedimento, o tensionamento metapolítico programado da organização do existente, fora também da política stricto senso e sem envolver, a princípio ou necessariamente, a referida ausência de controle. Essa ambigüidade positiva mostra que o conceito de transpolítica pressupõe ruptura possível de seu vínculo interno - só aparentemente exclusivo - com o universo sociotecnológico instituído e pode ser concebido, com inflexões diferenciais, como traço idiossincrático de uma forma particular de mobilização da categoria da crítica em relação ao e/ou contra a configuração do existente. Perceber tais nuances epistêmicas é fundamental para compreender como o caráter inadministrável, não-gerenciável e incontrolável dos fenômenos e tendências contemporâneos por parte das instituições modernas convive, no mesmo conceito, com a proposta de contrapolitização do real e de sua empiria processual transpolítica.

O princípio da politização abordado neste ensaio implica, pois, a transpolítica em acepção específica, embora a transpolítica per se, isto é, tal como se põe na literatura ensaística especializada (ibidem), 
não pressuponha tal princípio. Nessa perspectiva, a expressão politização transpolítica não deixa de encerrar certo pleonasmo (fora, claro, do plano dos significantes)-justificado, porém, pelas filigranas nela envolvidas. Transpolitizar, como categoria, teria, assim, a vantagem de cumular a significação dos dois termos, sem ecos internos.

Politizar (ou transpolitizar) é, em síntese, mais que tomar consciência da própria transpolítica como fenômeno contemporâneo e da transpolitização da vida social como processo multilateral dela derivado: Politizar é tensionar/desafiar diretamente o real de maneira que 0 questionamento (teórico-prático) não se subordine nem se reduza aos elementos constitutivos das instituições modernas.

Trata-se de um projeto reflexivo que, no âmbito estético e fora dele, não pode ser realizado - nunca é demais frisar - senão pelo crivo de uma crítica teoricamente reconstituída, epistemologicamente reavivada e metodologicamente reorientada ${ }^{23}$.

Mutatis mutandis, em tempos dromocráticos avançados, a arte precisa nutrir-se do paradoxo de sua própria inserção contextual: precisa ser tensionalmente identitária ao seu objeto, o mundo tecnológico transpolítico. Isso significa: mimese (o que também implica a fatoração do suporte) e, ao mesmo tempo, reserva radical - desconfiança a priori a partir de dentro. A politização ou é imanente ou não o é.

Doravante, a repolitização da arte (na acepção aqui sugerida) deve, assim, levar em conta a transpolítica da civilização mediática avançada e, em sentido inverso e simultâneo, lidar/“jogar" com ela atentando contra os seus fundamentos, manifestações e tendências, sem utilizar as categorias que sustentam o imaginário político instituído, renúncia consciente que a produção artística pós-68, em especial, não tem, de toda forma, deixado de exercitar de maneira abundante e diversificada.

Se, nessa esteira, (trans)politizar a arte significa, especificamente, politizar a relação com o insight e com o projeto artístico, com o processo criador, com os materiais e suportes, com

23. Uma abordagem mais acurada tanto sobre a natureza da crítica e da politização, quanto sobre como elas se configuram no campo da tecnoarte avançada escapa evidentemente ao presente ensejo. Parâmetros mais avançados a respeito, exclusivamente relacionados ao primeiro tema, no que ele implica a cultura pósmoderna; encontram-se em Trivinho (2001a, p. 161-174). 
as técnicas utilizadas, com a obra e sua destinação, com o público e com o contexto social-histórico (imediato e mediato), tal premissa fixa e refunde, em seu pontilhado, o sentido seqüencial da elocução. No limite, sob a radicalização necessária das hipóteses, politizar significa, como tese prioritária e aberta, questionar a tecnociência, sua natureza e suas tendências predominantes, através da estética permitida e produzida a partir da própria tecnociência; e, simultaneamente, explorar os limites desta contra ela mesma - o que, por certo, não implica somente questionar, pela arte de ponta, o mundo fundado na racionalização e no cálculo informáticos ${ }^{24}$. Em perímetro mais estrito, politizar significa, tout court, jogar o conservadorismo latente das técnicas, da tecnologia e dos media contra ele mesmo - vale dizer, os materiais e suportes contra eles mesmos -; e, por pressuposto, em perímetro mais alargado, (jogar) a cibercultura contra ela mesma, a dromocracia contra ela mesma, o cyberspace contra ele mesmo, e assim por diante ${ }^{25}$. Trata-se, numa palavra, de pentear o ciberufanismo a contra-pêlo ${ }^{26}$.

24. Evoca-se, aqui, obviamente, a arte digital dotada de autonomia integral em relação à lógica do mercado.

25. Esses apontamentos não vislumbram, muito menos encerram, evidentemente, nenhum programa para a arte; não pressupõem, absolutamente, a renovação do ultrapassado adágio de seu engajamento institucional ou, pior, partidário. Sequer sugerem o desencadeamento de um modelo de arte dromocrática, tampouco de seu oposto, a arte da desaceleração. Antes, chamam, com ênfase, a atenção para um fato óbvio e, por isso, olvidado. A rigor, a arte não se define pelo uso puro e simples dos materiais e suportes, mas na e pela relação específica que estabelece consigo mesma, com sua história (a partir da relação técnica e estética com aqueles) e com a dinâmica material e simbólica do contexto social-histórico. É em virtude desse núcleo de referência que determinada proposta estética estabelece ruptura com as tendências artísticas herdadas, sela a sua mensagem aos contemporâneos e legitima os horizontes que vislumbra. Relação comr é de critério, pois, nesse âmbito, que se trata. Isso significa, em suma, tão-somente aceno - aqui feito - para um princípio doravante fundamental em arte, a saber, o da necessidade de produção, por tal ou qual vertente estética, de tensão (tanto mais conceitualmente firme quanto possível) com o imperativo da velocidade e com o modo de organização do mundo nela fincada e por ela fomentada.

26. Para reescrever a estrutura de uma conhecida expressão certa vez usada por Banjamin, no âmbito teórico da filosofia da história. Se a história, como processo de disputa, distribuição e consolidação de poder não é senão a história dos vencedores - enquanto os vencidos jazem no chão, em meio à destruição generalizada, que remanesce depois invisível, sempre indiferentemente pregressa, sem possibilidade de redenção -, era preciso, sugeriu Benjamin, penteá-la a contra-pêlo. 
Somente essa compreensão transpolítica crítica do. contexto e do social-histórico - crítica de si mesma, antes de tudo - está à altura do desafio lançado pelos fenômenos tecnológicos contemporâneos e, por isso, pode encará-la de frente sem ser "vista" como extemporânea pela "inteligência" segredada do próprio desafio como processo, mesmo que a sua eficácia simbólica e/ou prática (a da mencionada compreensão transpolítica) tenha de ser sempre posta em dúvida. Nisso reside o sentido pleno da transpolitização da produção artística como contrapolitização determinada do real transpolítico. Transpolitizar o real pela arte é pôr em cheque a transpolitização operada pela própria dromocracia cibercultural. De todas as formas de produção cultural (tomadas na acepção antropológica) atualmente prevalentes - incluindo a ciência e o jornalismo -, somente a arte, com sua incomparável liberdade (ainda que condicional) de criação semiótica, parecer estar à altura da dimensão abstrata envolvida no cumprimento dessa contra(trans)politização.

A possibilidade de explicitação da violência simbólica difusa através de um princípio de desafio que lhe é identitário não denota senão a suma importância da posição da arte e de sua função estética no processo de articulação internacional dos esforços de avaliação crítica da lógica da cibercultura. Quer-se crer que, a esse respeito, o presente estudo, embora sinóptico, tenha sido, de alguma forma, útil.

Se, conforme antes sinalizado, politizar significa, em sentido genérico, trazer à luz os dados empíricos da época, a fim de arrancála do limbo sombrio que mantém o seu modus operandi tecnológico, simbólico e imaginário geralmente livre de questionamento, a ativação estética do princípio teórico sugerido - e isto em fidelidade à complexidade progressiva das práticas artísticas e em nome da diversidade das formas e expressões até mesmo em uma única ramificação ou tendência - não deixaria de ser, na atualidade, um dos mais nobres préstimos intelectuais que a arte, como reflexão específica sobre a existência, poderia prestar à história contemporânea do pensamento.

Esse procedimento, com efeito, somente poderia ser levado a cabo - sublinhe-se - pelo prisma de uma categoria incondicional 
de crítica, desprovida, por pressuposto, da ilusão corrente de se considerar que tais e quais aspectos particulares das tecnologias interativas e do cyberspace são, em si - mormente pelas possibilidades pragmáticas que entreabrem -, positivos ou vantajosos $^{27}$. O procedimento contém, como valor imensurável, o que, de resto, continua a ser verdade histórica em estética: a autonomia mais radical que sempre se pode buscar, mesmo a duras penas, em determinada época, sempre dignificou, em reverso - onde o ápice é mais alto -, o labor da arte.

\section{Bibliografia}

ADORNO, T. W. 1970. Teoria estética. Lisboa: Ed. 70.

BENJAMIN, W: A obra de arte na época. de sua reprodutibilidade técnica. In: LIMA, L. C. (Org.). Teoria da cultura de massa. 2. ed. Rio de Janeiro: Paz e Terra, p. 209-244.

BERMAN, M. 1987. Tudo que é sólido desmancha no ar: a. aventura da modernidade. São Paulo: Companhia das Letras.

BOURDIEU, P. 1982. A economia das trocas simbólicas. São Paulo: Perspectiva. (Col. Estudos.)

1983. A economia das trocas lingüísticas. In: ORTIZ, R. (Org.). Pierre Bourdieu: Sociologia. São Paulo: Ática, p. 156183. (Col. Grandes Cientistas Sociais, 39). Brasil.

2002. O poder simbólico. 5. ed. Rio de Janeiro: Bertrand

CELAN, P. 1999. Cristal. São Paulo: Iluminuras.

NEGRI, A.; HARDT, M. 2001. Império. Rio de Janeiro; São Paulo: Record.

27. Não é raro, na produção ensaística direta ou indiretamente versada na problemática da cibercultura, que o ciberufanismo vigente entre por essa porta (em geral, da frente) da construção teórica. No âmbito da reflexão sistemática, a concessão metodológica, em especial a fincada em simpatias pré-simbólicas e protoconceituais para com determinados aspectos do objeto, representa o caminho mais curto para a afirmação - voluntária ou involuntária - da ingenuidade política. 
TRIVINHO, E. 1999. Cyberspace: crítica da nova comunicação. São Paulo: Biblioteca da ECA/USP. 466 p.

. 2001a. O mal-estar da teoria: a condição da crítica na sociedade tecnológica atual. Rio de Janeiro: Quartet.

. 2001b. Horizonte negativo da arte na era da saturação estética. Significação-Revista Brasileira de Semiótica. São Paulo: Annablume, n. 15, p. 61-106.

2002. Velocidade e violência: dromocracia como regime transpolítico da cibercultura. In: PORTO, S. D. (Org.). A incompreensão das diferenças: 11 de setembro em Nova York. Brasília: IESB, p. 257-272. (Série Comunicação).

2003. Cibercultura, sociossemiose e morte: sobrevivêncià em tempos de terror dromocrático. Fronteiras: estudos midiáticos, São Leopoldo, v. V, n. 2, p. 97-124.

.2006. A condição transpolítica da cibercultura: ruína do Estado e da política na civilização mediática avançada. São Paulo: 2005. Cópia reprográfica e digital. 15p. [Texto a ser publicado na revista Famecos: mídia, cultura e tecnologia, editada pelo Programa de Pós-Graduação em Comunicação Social da PUC/RS, Porto Alegre: EDIPUCRS, n. 31, dez. 2006.]

VIRILIO, P. 1984a. L'horizon négatif: essai de dromoscopie. Paris: Galilée.

. 1984b. L'espace critique. Paris: Christian Bourgois.

.1984c. Guerra pura: a militarização do cotidiano. São Paulo: Brasiliense.

. 1996. Velocidade e política. São Paulo: Estação Liberdade. . 2002. L'inertie polaire: essai. Paris: Christian Bourgois 